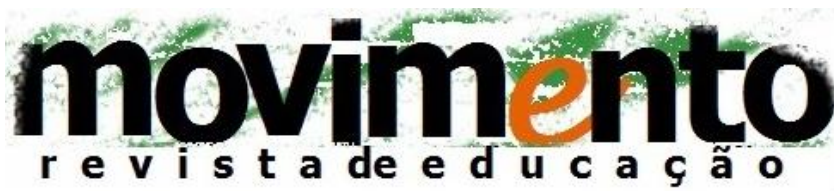

faculdade de educação - programa de pós-graduação em educação universidade federal fluminense issn 2359-3296

ano 3 número 4 - 2016

\section{PRÁTICAS PEDAGÓGICAS E SUPERAÇÃO DE PRECONCEITOS: discutindo gênero e diversidade na escola}

\author{
Aldenora Conceição de Macedo' \\ Ivana Gonçalves de Oliveira² \\ Jaqueline Aparecida Barbosa ${ }^{3}$
}

\section{RESUMO}

Cotidianamente meninas e meninos são discriminadas/os por não apresentarem comportamentos condizentes com as feminilidades e masculinidades privilegiadas em nossa sociedade e as crianças negras não encontram socialmente um ambiente propício para o desenvolvimento saudável da autoestima no que tange ao pertencimento racial. Quando a escola corrobora tais situações atua na contramão do que se espera e pode consolidar preconceitos e estimular discriminações. Apresentamos, então, esta reflexão que não se configura como um projeto pontual na área de gênero, raça e sexualidade, mas como sistematização de ações cotidianas por nós adotadas que questionam condutas impostas como corretas, buscando a desconstrução de preconceitos recorrentes no ambiente escolar. Concluímos que essas ações contribuíram para que as crianças se mostrassem mais atentas às atitudes preconceituosas ocorridas não só na escola, mas também em outros espaços de convivência, influenciando positivamente nas relações estabelecidas por elas.

Palavras-chave: Relações de gênero; Relações étnico-raciais; Diversidade; Educação.

Titulo: PRÁCTICAS PEDAGÓGICAS Y SUPERACIÓN DE PREJUICIOS:

Discusión sobre género y diversidad en la escuela

\footnotetext{
${ }_{1}$ Mestranda em Direitos Humanos e Cidadania pela Universidade de Brasília. Licenciada em Pedagogia pela Faculdade Evangélica de Brasília e professora de Educação Básica no Governo do Distrito Federal. Endereço eletrônico: aldenora.acm@gmail.com

2 Mestranda em Educação pela Universidade de São Paulo - USP, na linha de pesquisa Sociologia da Educação. Professora da Educação Básica pela Secretaria de Educação do Distrito Federal. Endereço eletrônico: ivana.g.oliveira@gmail.com

${ }^{3}$ Mestranda em Educação pela Universidade Federal de Goiás - UFG, na linha de pesquisa Educação, Trabalho e Movimentos Sociais. Professora da Educação Básica pela Secretaria de Educação do Distrito Federal. Endereço eletrônico: jaq.usp@gmail.com
} 


\section{RESUMEN}

Cotidianamente niñas y niños son discriminadas/os por no tener los comportamientos propios de las feminidades y masculinidades de privilegio en nuestra sociedad. Además, niños/as negros/as no encuentran socialmente un entorno propicio para el adecuado desarrollo de su autoestima en lo que se refiere a súper tenencia racial. Cuando la escuela refuerza tales situaciones, actúa en el sentido contrario de lo esperado y puede consolidar los prejuicios y estimularla discriminación. Presentamos, así, una reflexión que no se configura como un proyecto en la área de género, raza y sexualidad, sin embargo como una sistematización de acciones cotidianas que desarrollamos para problematizar conducta impuestas como correctas, buscando la desconstrucción de prejuicios recurrentes en el espacio escolar. Llegamos a la conclusión de que estas acciones ayudaron a los/as niños/as a se mantener más atentos a actitudes prejuiciosas que ocurren no sólo en la escuela pero también en otros espacios sociales, influyendo positivamente en las relaciones establecidas por ellos.

Palabras clave: Relaciones de género; Relaciones étnicas y raciales; Diversidad; Educación.

\section{Introdução}

Esse relato é fruto das nossas discussões e reflexões como professoras de uma escola pública da periferia do Distrito Federal. A escola atende turmas de Educação Infantil, séries iniciais do Ensino Fundamental e educação especial. Nós, além de atuarmos em todas estas etapas e modalidades, procuramos sempre participar de formações continuadas voltadas para o trabalho com gênero e raça, ocasiões nas quais pudemos discutir questões que faziam parte das nossas inquietações e que embasam nossa atuação. Desta forma, neste texto, apresentamos uma série de reflexões acerca do cotidiano escolar e comentamos algumas intervenções que não devem figurar como respostas definitivas para uma questão tão complexa quanto o trabalho com gênero e diversidade na escola - não é essa nossa pretensão, mas sim sistematizar algumas práticas que nós, professoras preocupadas com estes temas, realizamos cotidianamente.

De início é importante dizer as ações relacionadas a estes assuntos se encontram numa zona limítrofe entre o que se convencionou chamar de currículo prescrito, relacionado aos dispositivos legais e políticas públicas, e o currículo oculto, entendido como 
todos aqueles aspectos do ambiente escolar que, sem fazer parte do currículo oficial, explícito, contribuem, de forma implícita para aprendizagens sociais relevantes. $O$ que se aprende no currículo oculto são fundamentalmente atitudes, comportamentos, valores e orientações. (SILVA, 2001, p. 78)

Consideramos que nossas ações se localizam neste limiar porque se inserem num campo fluido e subjetivo, no campo das atitudes e valores. Apesar disso, se amparam num sólido arcabouço de políticas públicas vigentes, com produção de material e grande apoio público para serem realizadas. Tais ações são de grande importância, pois colaboram para a reflexão e desconstrução do senso comum, aqui relacionado aos pensamentos preconceituosos e atitudes discriminatórias presentes nos ambientes de convívio das crianças.

Entendemos a escola como uma instituição social com grande influência na formação e socialização dos indivíduos e que, neste sentido, participa de forma decisiva na produção, manutenção ou subversão de padrões de comportamento, influenciando nos âmbitos mais íntimos da existência, como na constituição da autoestima, no reconhecimento de uma identidade de gênero, na consciência de pertencimento racial, entre outros.

Problematizar a atuação da instituição escolar, implica levar em conta também o contexto em que professoras/es foram formadas/os e se formam continuamente, pois suas práticas pedagógicas se dão a partir das diversas bagagens acadêmicas e pessoais que acumulam ao longo da vida. Muitas vezes estes valores e conhecimentos prévios adquiridos foram embasados em perspectivas do senso comum, que não problematizam desigualdades de gênero e raça. Assim,

O que se ensina na escola é uma reinterpretação de conhecimentos e saberes disponíveis na cultura por meio de um prolongado processo de reflexão, individual e coletiva, sobre o sentido desta. Assim, como consequência, é uma recriação - nem sempre feliz - dos saberes considerados valiosos pela sociedade. (LLAVADOR apud SACRISTÁN, 2013, p. 191) 
Neste panorama, em que a escola pode tanto produzir e consolidar preconceitos quanto combatê-los, há inúmeras justificativas para trabalharmos com a abordagem de temáticas relacionadas a gênero, sexualidade e relações étnicoraciais, trabalho este que consideramos necessários desde a educação infantil e anos iniciais do ensino fundamental, públicos-alvo para com os quais este trabalho pretende contribuir na desconstrução de preconceitos e superação de todas as formas de discriminação.

GÊnero e RaÇa na escola - um debate fundamental

Diversos estudos e documentos oficiais indicam a relevância do debate acerca das relações de gênero e raça no ambiente escolar. Os trabalhos de Carvalho (2001; 2004; 2009), por exemplo, demonstram que as percepções sobre gênero e raça influenciam o modo de avaliação que são realizadas para com as crianças, pelas professoras.

\footnotetext{
Para além das questões de desempenho na aprendizagem, é preciso uma reflexão crítica constante a fim de que a escola possa ser palco de transformação e não de reiteração ou até mesmo de ampliação de relações desiguais e hierarquizadas. São indispensáveis, no sistema escolar, discussões sobre as relações de gênero e de raça [...] para que a escola possa contribuir no combate às desigualdades de gênero e raça, dentro e fora de seus muros. (CARVALHO, 2009, p. 121-122)
}

No documento Gênero e diversidade sexual na escola: reconhecer diferenças e superar preconceitos, encontramos um diagnóstico sobre gênero e diversidade em educação que aponta para a necessidade de se analisar as relações de gênero a partir da complexidade que atinge de modo diferente meninos e meninas. Temos uma tendência crescente de maior fracasso escolar entre os meninos, geralmente atribuídas "à socialização voltada para o trabalho, à realidade econômica e à exacerbação de um único modelo de masculinidade na escola" (BRASIL, 2007, p. 31). O documento aponta ainda que

A produção sobre fracasso escolar e sua interface com as desigualdades de gênero é ainda incipiente. Ao mesmo tempo, 
estudos mostram a existência de uma relação entre as masculinidades e feminilidades e o melhor e pior êxito escolar de cada um dos sexos, que pode ser intensificado conforme o pertencimento social e racial. (BRASIL, 2007, p. 32)

Preconceitos e discriminações que envolvem gênero, raça e sexualidade são, também, motivadores de violência no cotidiano escolar, como demonstra a pesquisa coordenada por Abramovay (2009), intitulada Revelando tramas, descobrindo segredos: convivência e violência nas escolas ${ }^{4}$, que teve como principal objetivo "o conhecimento da situação atual das escolas da rede pública de ensino do Distrito Federal no que diz respeito à complexidade das relações sociais, representações e violências que ocorrem nesses espaços" (p. 425). Ela traz números alarmantes acerca das diversas questões que contribuem para os conflitos no ambiente escolar, como o preconceito e a discriminação com relação às manifestações de gênero e sexualidade e também raciais. Assim, nesta pesquisa, Abramovay (2009) constatou em relação à homofobia que

[...] esta se vincula a concepções sobre o que seria uma sexualidade dita correta ou normal, legitimada por padrões culturais que condenam práticas não-heterossexuais. Mais da metade dos estudantes e dos professores declararam já terem presenciado cenas discriminatórias contra pessoas que são ou parecem ser homossexuais. Embora com um percentual bastante menor, foi considerável também o número de alunos que afirmaram ter sofrido com esse tipo de discriminação. (ABRAMOVAY, 2009, p. 427-428, grifos nossos)

E, no que se refere à desigualdade de gênero,

[...] investigou-se os valores e moralidades sobre o que meninos e meninas fazem, falam, pensam e sentem. Foi constatado que, embora as práticas e valores pedagógicos tenham se modificado no que se refere às relações entre os gêneros, continuam presentes determinados padrões tradicionais sobre os papéis e atividades. Nesse sentido, algumas atividades desenvolvidas no meio escolar são marcadas por ideias de que existem conjuntos de características que seriam próprias majoritariamente de homens ou de mulheres, existindo, por vezes, uma atribuição polarizada de diferenças de gênero, que tem como consequência a criação de arranjos sociais desiguais entre os alunos. (ABRAMOVAY, 2009, p. 431, grifos nossos)

4 Trata-se de grande pesquisa conduzida pela Rede de Informação Tecnológica LatinoAmericana (RITLA) a partir de demanda da Secretaria de Educação do DF. Abrangeu 84 escolas da rede pública que atendiam $5^{\underline{a}}$ série (atual $6^{\circ}$ ano) do Ensino Fundamental até o $3^{\circ}$ ano do $\mathrm{s} \backslash \mathrm{z}$ 
Percebemos que tanto a violência homofóbica quanto as desigualdades de gênero se relacionam com a homogeneização de comportamentos, considerando desviante toda/o aquela/e que não se encaixa num padrão único esperado para meninos e meninas. Já com relação à discriminação por raça/cor, o estudo aponta que relações raciais assimétricas foram relatadas pelas/os alunas/os como existentes

[...] tanto fora quanto dentro do espaço escolar. Os dados indicam que mais da metade dos estudantes já presenciou alguma forma de manifestação de preconceito racial dentro dos colégios. As falas vão além da simples constatação da existência do preconceito e apontam, também, para situações de constrangimento e exclusão, principalmente de pessoas negras do convívio social, com prejuízo para a vida escolar. Foram numerosos os comentários referentes aos apelidos e xingamentos discriminatórios, demonstrando que a simples existência da diversidade de raça/cor, ou a pretensa promulgação da miscigenação como valor, não é suficiente para barrar a existência de preconceito. (ABRAMOVAY, 2009, p. 429, grifos nossos)

No que diz respeito às relações étnico-raciais ainda é muito comum que haja, nas escolas, uma negação da existência de discriminação racial, opinião essa emitida não só na escola, mas em toda sociedade, e pode ser facilmente solapada quando se ouvem os sujeitos implicados neste dia-a-dia preconceituoso. A negação é uma característica muito comum do racismo brasileiro e dificulta o enfrentamento do problema. É importante ressaltar que

[...] o fato de, muitas vezes, o racismo não ser explicitado verbalmente, não o torna menos presente e agressivo no dia-a-dia dos alunos e alunas negros(as), pois há muitas outras maneiras pelas quais ele se manifesta na cultura brasileira: privilegiam-se os brancos, reconhecese este biotipo como aquele que representa a beleza estética e intelectual da raça humana e ainda acha-se normal que este segmento da população detenha o poder político, econômico, cultural e religioso. (BRASIL, 2005 p. 110)

Neste sentido é necessário um olhar atento para perceber o modo como a discriminação racial se manifesta na escola. A resistência que observamos nas/os colegas de trabalho em implementar a Lei 10639/2003, que institui a obrigatoriedade do ensino da história e cultura africana e afro-brasileira, por 
exemplo, é, também, bastante emblemática. Ao propor ações relacionadas ao enfrentamento do racismo nos deparamos com diversas justificativas para a não abordagem, com argumentos que vão da negação dos problemas de discriminação à alegação de não se sentir à vontade por desconhecimento da temática (que muitas vezes não vem acompanhada de uma disposição formativa) até, enfim, a tentativa de diluição do assunto em outros temas mais amplos, gerando uma abordagem superficial e pouco efetiva do tema.

Certamente que na escola, entendida como espaço integrante da sociedade, sempre haverá inúmeras manifestações de preconceito e negação, isso é esperado, porém esta instituição possui papel formativo que the é intrínseco e, nesse sentido, deve construir uma postura proativa que possibilite a compreensão e superação dessas manifestações. A formação escolar precisa articular os saberes formais à realidade, pautando-se no respeito às diferenças.

\section{Enfrentando Preconceitos Na Escola - algumas ações}

Neste espaço vamos sistematizar as ações cotidianas desenvolvidas em nossas salas de aula que têm como objetivo atuar no enfrentamento ao racismo e ao sexismo, principalmente, e que acabam contribuindo para o questionamento de atitudes que se configuram como homo/lesbo/bi/transfóbicas. É importante dizer que não temos com esse trabalho a intenção de dar receitas, mas sim de mostrar que, com um aprendizado contínuo e olhares sensíveis ao tema, é possível ter uma prática diária que se configure como uma tentativa de não reproduzir as discriminações com relação a gênero e sexualidade e/ou ao racismo.

-Relações interpessoais e divisão por sexo: Abolimos as filas e outras situações nas quais as crianças são divididas por sexo. Acreditamos que a ideia de polarizar as crianças a partir de seus sexos cria um imaginário, em primeiro momento, de que esse apartamento é algo necessário. Tal ação refletirá, em nosso entendimento, nas demais relações escolares, atrapalhando brincadeiras e trabalhos coletivos, por exemplo. Incentivamos, assim, a convivência e a troca de experiências entre todas as crianças, não adotamos duplas mistas como punição e articulamos brincadeiras em que todas/os possam participar juntas/os. 
-Padronização por cores: Não estabelecemos cores que padronizem as crianças a partir de um ideal de gênero feminino ou masculino, pois, para nós, fomentaríamos dessa maneira uma simbologia de determinismo e repressão que atuaria no impedimento à criança de desenvolver sua identidade própria com liberdade e protagonismo. Buscamos, portanto, um tratamento mais igualitário para que possam, desta maneira, construírem suas próprias experiências e descobertas.

- Sexismo e brincadeiras: Procuramos não ressaltar o sexismo com as lembrancinhas para as crianças. Ao presenteá-las, em algum momento, optamos por brinquedos não muito estereotipados pelo gênero, os tidos como unissex, ou ainda, nos casos em que há caixas de brinquedos na sala, por exemplo, não separamos por sexo - caixa das meninas, caixa dos meninos. Voltamos aqui à importância de que o brincar não pode ser limitado àquilo que o senso comum atribui ao sexo biológico da criança, uma vez que isso tolhe as vontades de se aventurar e descobrir também a partir daquilo que não é estipulado como próprio para elas. Do mesmo modo, nas brincadeiras que se relacionam às profissões, procuramos fazer com que as crianças entendam que mulheres e homens são igualmente capazes de exercer qualquer prática cotidiana e profissional.

- Representatividade e constituição de identidade: Incluímos, na decoração da sala de aula, ilustrações que representem crianças brancas e negras, meninas e meninos. Procuramos representar os diversos tons de peles das crianças, para desmistificar a expressão limitada cor de pele, a qual também abolimos do discurso em sala.

- Reconhecimento e estereótipos: Problematizamos o trabalho com as datas comemorativas que geralmente são usadas de forma reducionista e passam, nesse sentido, uma ideia equivocada daquele fato ou uma visão deturpada/anacrônica de grupos sociais, por exemplo, como vemos em datas como o dia do índio, descobrimento do Brasil, dia da abolição da escravatura, dia da mulher. Uma das maneiras de subverter essa prática de forma viável é utilizar nas atividades cotidianas textos e imagens que passem uma visão positiva destes grupos que geralmente são marginalizados no discurso escolar. Para isso realizamos leituras sobre mulheres cientistas, sobre personalidades negras que extrapolam estereótipos socialmente construídos, trazemos exemplos de beleza negra e indígena, realizamos leituras de narrativas tradicionais e outros textos que ampliem a visão de mundo e perspectivas históricas que as crianças carregam com elas.

- Concepções e preconceitos: Problematizamos concepções sexistas, racistas, homo/lesbo/bi/transfóbicas trazidas pelas crianças. Aproveitamos como momento disparador falas e ações das crianças que carreguem, em qualquer medida, nuances de preconceitos. Assim, levamos as problematizações para a turma como proposta de debate e discussão, mediando sempre para que se mantenha o caráter formativo do debate. 
-Diversidade familiar e afazeres domésticos: Conduzimos reflexões sobre modelo familiar e, como consequência, abordamos a questão da divisão dos afazeres domésticos. Incentivamos, dentro das possibilidades e limites da escola, que meninos auxiliem nos afazeres que são praticados em sua maioria apenas pelas meninas. Mostramos a importância de divisão de tarefas e debatemos sobre a sobrecarga que ainda é delegada às meninas/mulheres.

-Estereótipos escolares: Evitamos utilizar as já naturalizadas taxações acerca das crianças: meninos como bagunceiros e meninas como fofoqueiras etc. Agimos desta mesma maneira também para com suas famílias: entre outras ações neste sentido está a de procurar entender a realidade de cada família antes de tratar, generalizadamente, a mãe, como única responsável pela educação e cuidado das crianças ou acompanhamento escolar.

- Linguagem e discurso: Temos muita atenção com a linguagem empregada nos diálogos e discursos dentro da escola. Evitamos a utilização de termos que impõe como norma a supremacia do masculino e a universalização do homem, no qual as mulheres precisam se sentir incluídas mesmo quando são maioria. Também tomamos muito cuidado para não utilizar termos e frases feitas que, apesar de serem de uso recorrente, apresentam um conteúdo racista ou machista. Tentamos, sempre que possível, incutir esta ideia na escola como um todo.

ConvivÊNCIA ENTRE PAREs - percepções e subjetividades

"É preciso uma aldeia inteira para educar uma criança." (Provérbio africano)

A educação integral é aquela que leva em consideração as especificidades das/os estudantes e busca a formação que possibilite uma inserção participativa e atuante na sociedade. Fomenta, para tanto, a constituição de uma identidade própria alicerçada pela visão crítica de mundo a partir de seu lugar na sociedade. Traz subsídios para o exercício pleno da cidadania e valoriza a pluralidade de viveres e saberes. Reconhece na escola local privilegiado de transformação e por isso mesmo não a enxerga como um microssistema apartado da sociedade, mas como um constitutivo social perpassado por todas as problemáticas do cotidiano, levando em conta, sobretudo, as particularidades dos sujeitos que a compõe (BRASIL, 2009). 
Nesse sentido entendemos que a criança, também no ambiente escolar, é responsabilidade de todas/os, não apenas da educadora ou educador vinculada/o à sua escolarização em determinado período. A partir dessa ideia de responsabilidade coletiva descreveremos a seguir alguns apontamentos acerca da participação de sujeitos, restritos à instituição escolar, e sua relação com a abordagem da diversidade.

\section{Estudantes}

Basta um olhar um pouco mais atento para perceber as diversas situações nas quais as crianças reproduzem preconceitos de gênero e raça em situações de interação e brincadeiras. É bastante comum, tanto entre as menores como entre as mais crescidas, que a criança, na realização de uma atividade considerada feminina ou masculina enfrente uma interdição por parte de alguma outra, geralmente expressa em frases como não é coisa de menino, não é coisa de menina. Ofensas homofóbicas e sexistas também são bastantes comuns em situações de conflito ou quando uma criança apresenta um comportamento considerado não adequado de acordo com seu sexo.

Observamos, com facilidade, a divisão espontânea entre meninos e meninas em momentos de brincadeiras ou na escolha de lugares em sala, quando feita livremente pelas crianças. Esses comportamentos refletem preconceitos do senso comum, muitas vezes reforçados na escola, que utilizam fortemente 0 sexo como critério de organização das atividades.

No que se refere às relações raciais também podemos relatar diversas situações em que observamos atitudes discriminatórias no grupo de crianças. Essas atitudes vão desde ofensas e utilização de termos depreciativos até 0 preterimento de crianças negras por seus pares na realização de atividades. Enfrentar esses problemas e desconstruir tais preconceitos no cotidiano escolar nos coloca diante de muitas dúvidas sobre a melhor abordagem a se utilizar, no 
entanto, somente a intervenção nos possibilita criar um reportório que nos auxilie nessas situações.

Ao utilizarmos outros modos de organização das atividades é comum, por exemplo, que as crianças solicitem que façamos divisões de meninas e meninos e até mesmo apresentem resistência às atividades com agrupamentos mistos, porém, aos poucos, insistindo nas organizações nãos sexistas para com as crianças, percebemos interações mais positivas entre os grupos que passaram a aceitar com mais naturalidade, por exemplo, meninas jogando futebol ou outros jogos considerados masculinos e, meninos nas brincadeiras de casinha ou outras brincadeiras consideradas femininas.

Da mesma forma enfrentar o racismo exige um olhar sensível para escolher a maneira mais adequada de se abordar o preconceito, sempre com o cuidado de que isso não cause constrangimentos ou reforce situações de discriminação já vivenciadas pelas crianças. Uma de nossas ações nesse sentido, embasada nas Orientações Para a Implementação da Lei 10.639/2003 (BRASIL, 2005), é a de trazer referenciais de beleza étnico-raciais positivos para dar subsídios à construção de uma autoimagem valorativa. Observamos, assim, crianças orgulhosas de seus cabelos crespos e cacheados ou, em outra abordagem, por exemplo, após possibilitar o uso de giz de cera com diversas cores para representação dos tons de suas peles, crianças escolherem, com naturalidade, o tom que julgavam mais adequado para retratar a si mesmas e suas famílias, muitas vezes, diversas em sua composição racial.

Dentro da escola todo e qualquer momento pode ser motivador para se debater o preconceito, mas a brincadeira é, sem dúvida, um dos momentos mais propícios tanto para a simples observação como para intervenções que favoreçam a superação deste. Ao realizar uma brincadeira de chute a gol (ou alguma outra atividade de movimento corporal) algumas meninas se mostravam tímidas e pouco confiantes, mas com algumas falas tranquilizadoras e de incentivo notamos que elas vão se sentindo mais à vontade em se desafiarem. 
Ao observar as interações das crianças nos momentos de brincadeiras, notamos a necessidade de articular intervenções realizadas em situações específicas de discriminação com um trabalho contínuo de desconstrução de preconceitos. Em uma turma de educação infantil, por exemplo, uma criança negra sempre recorria à professora para reclamar que as/os colegas não a deixavam participar da brincadeira. Após mediação da professora as outras crianças permitiram a entrada da menina na atividade, no entanto, logo em seguida desistiram da brincadeira para deixá-la de fora novamente. A observação foi então fundamental para perceber que a intervenção estava sendo insuficiente, sendo necessário um trabalho mais sistemático para cessar as manifestações discriminatórias contra essa criança especificamente, ao lado de uma abordagem que favorecesse a desconstrução de preconceitos raciais de forma mais geral.

As interações entre as crianças revelam suas visões de mundo e o modo como compreendem as relações, trata-se, portanto, de uma dimensão fundamental para observar de que maneira o trabalho de valorização da diversidade está repercutindo no grupo e quais serão os próximos passos a serem dados nesse longo processo.

\section{Educadoras/es}

A escola pode se constituir como um espaço coletivo de trocas significativas e aprendizagens não só para as crianças que circulam neste espaço, mas também para nós, adultas/os, que convivemos cotidianamente com todas/os que integram este ambiente, possuidoras/es de formações e experiências de vida diversas. Assim, uma maneira de transformar a escola num espaço de respeito à diversidade em todas as suas expressões seria a troca de experiências formativas entre os sujeitos que ali se encontram. Infelizmente, entretanto, os temas da diversidade, principalmente os que se referem à sexualidade e ao respeito às diversas manifestações religiosas, enfrentam muita resistência no 
interior da escola, inclusive entre o próprio corpo docente, o que impede a inserção destes temas no cotidiano escolar, fazendo com que as/os professoras/es que possuem alguma formação na área não consigam disseminar esse conhecimento.

Barbosa e Paz (2015) em um trabalho que versa sobre a percepção de professoras/es sobre o curso Gênero e Diversidade na Escola - GDE e a influência dele em suas práticas, apontam que as/os colegas de profissão têm um papel fundamental na implementação (ou não) do que pode se chamar de educação para a diversidade. Neste trabalho as autoras apontam que muitas/os docentes mencionaram a vontade de trabalhar com o tema, de propor projetos audaciosos, mas disseram que se sentem, no geral, desestimuladas/os, ridicularizadas/os e/ou ignoradas/os pelas/os colegas de profissão. Nesta pesquisa apenas um professor que desenvolveu um grande projeto premiado como Escola promotora da Igualdade de gênero ${ }^{5}$ em 2014 afirma que foi muito elogiado por conta do trabalho desenvolvido e que recebeu algum apoio das/os colegas de profissão para dar prosseguimento ao projeto. Podemos sugerir com isso que a premiação dotou suas ações de certa positividade, conferindo legitimidade às práticas dele.

Não foram poucas as situações em que o grupo de docentes da escola na qual atuamos se opôs ao desenvolvimento de um trabalho sobre estes temas ou mesmo se recusou a repensar algumas ações que considerávamos equivocadas, como a execução diária de uma oração cristã no pátio da escola, por exemplo. No Distrito Federal, de acordo com a pesquisa coordenada por Abramovay (2010), considerando o grupo de alunas/os pesquisadas/os, "são os adeptos do candomblé os que mais reportam haverem sofrido discriminação religiosa" (ABRAMOWAY, 2010, p. 244). Também não faltam notícias de incêndios criminosos em terreiros e perseguição a membros de religiões de

5Trata-se de uma das categorias do "Prêmio Construindo a Igualdade de gênero", concurso anual que premia, em diversas categorias, redações, artigos científicos e projetos pedagógicos na área das relações de gênero e feminismos. Essa categoria foca em escolas que tenham desenvolvido, em ano(s) anterior(es) ao do concurso, projetos que coloquem a igualdade de gênero entre suas metas. 
matriz africana. Nada disso, entretanto, parece sensibilizar para a necessidade de uma abordagem desmistificada sobre estas religiões no ambiente escolar.

Não podemos deixar de apontar, ainda, os altos números da violência contra a mulher e dos crimes de ódio que têm como alvo a população LGBTTT ${ }^{6}$. O tema do combate à violência contra as mulheres recebe um pouco mais de apoio por parte de colegas, no sentido de se posicionarem como contrárias/os a essas práticas, mas ainda assim não há um entendimento de que algumas posturas adotadas na escola, ao ressaltar um só tipo de masculinidade, geralmente aquela que se afirma a partir da violência, pode incentivar este tipo de ação violenta contra mulheres. Com relação à sexualidade o quadro é ainda mais dramático: já ouvimos, muitas vezes, na sala de professoras/es que as pessoas só são homossexuais por falta de couro, ou, que se a família não corrigiu a sociedade corrige, num movimento claro de incentivo e aprovação da agressão contra as pessoas que não se encaixam nas normas e padrões heterossexuais.

Outra questão a ser levantada é a da religiosidade na escola, principalmente no que tange ao corpo docente e diretivo. Expressão que acompanha os seres humanos desde os primórdios, a religiosidade pode adquirir contornos salutares quando se orienta para crescimento espiritual e o respeito e acolhimento de outros seres humanos. Entretanto, se for tomada de forma fundamentalista por professoras/es, como já presenciamos ao longo de nossa trajetória profissional, impede que temas que tocam nos dogmas religiosos de docentes sejam trabalhados nas escolas e acaba pautando a ação de funcionárias/os públicas/os no exercício de sua função, ferindo o princípio da laicidade e da pluralidade religiosa que rege o Estado brasileiro. Concordamos que

A pluralidade de matrizes religiosas e de visões de mundo e perspectivas encerra em si a possibilidade de embates teóricos, teológicos e sociais, a depender de como cada religião significa o outro. Se existem correntes e religiões que tendem a respeitar e abarcar o diferente, como os movimentos de caráter ecumênico, existe também o pronunciado risco de se cair em uma heterofobia, que valoriza as diferenças, reais ou imaginárias, em proveito próprio, para

${ }^{6}$ Sigla para Lésbicas, Gays, Bissexuais, Travestis, Transexuais e Transgêneros. 
justificar preconceitos, discriminações e outros tipos de agressão. (ABRAMOVAY et al, 2010, p. 241)

Desta forma, quando convicções pessoais vinculadas a um determinado pensamento religioso são levadas para a sala de aula e para as discussões nos grupos de professoras/es, é difícil de contra argumentar em termos de direito à educação e adesão aos princípios expressos em documentos oficiais, pois debate-se sobre valores que se amparam em dogmas, que resistem aos argumentos que vão no sentido de respeito aos direitos humanos.

Neste sentido, as atividades que realizamos ficaram um pouco isoladas em nossas turmas, por dificuldades de estabelecer um diálogo profícuo com colegas de trabalho. Cabe ainda dizer que também encontramos parceiras/os de profissão que comungam de nossos ideais de valorização da diversidade, mas sempre em número muito menor do que as/os que se opõem a esse trabalho. Para melhorar esse dialogo seria importante a mediação da coordenação pedagógica e da gestão escolar, dimensão que abordaremos a seguir.

\section{Gestão}

Respeitando a hierarquia da organização escolar, sua importância para a formulação de projetos e seu papel decisório na concretização de mudanças de todas as ordens no ambiente escolar, nós sempre buscamos levar nossas inquietações à gestão da escola. Essa ação buscava uma adesão mais abrangente à pretendida abordagem igualitária da educação, pois almejávamos incentivar um nova identidade para a escola por meio da inclusão das temáticas da diversidade nos documentos da instituição. Essas investidas ocorriam em diversas reuniões, sobretudo nas que objetivavam determinar as temáticas e conteúdos a serem abordados nos planejamentos didáticos. Nessas ocasiões apresentamos ideias para inclusão e até mesmo projetos, já organizados, com a abordagem de gênero/sexualidade e raça, porém, em todas elas, gestão e/ou coordenação sempre mantiveram uma postura resistente frente às nossas 
propostas. Ficamos assim relegadas à desenvolver nossas ações num ambiente restrito à sala de aula e na convivência entre nossas turmas.

Buscando contextualizar esse relato consideramos importante trazer uma breve discussão a partir do modelo de gestão adotado pela Secretaria Estado de Educação do Distrito Federal (SEEDF), sistema de ensino no qual estamos inseridas, a Gestão Democrática de Ensino. A adoção desse modelo de gestão está previsto na própria Constituição Federal de 1988, mais precisamente no artigo 206, ao indicar a "gestão democrática do ensino público, na forma da lei" para a educação básica do país. No Distrito Federal a Lei № 4.751/20012 instituiu a Gestão Democrática do Sistema de Ensino Público do Distrito Federal, cuja finalidade, explicitada no Art. $2^{\circ}$, é "garantir a centralidade da escola no sistema e seu caráter público quanto ao financiamento, à gestão e à destinação." Para o cumprimento integral almejado na Lei é imprescindível que sejam observados os princípios exemplificados em sua redação.

Um desses princípios é indispensável nessa discussão, pois reafirma a necessidade de se incorporar à gestão da escola a obrigação e responsabilidade na busca de mecanismos para possibilitar uma prática pedagógica mais diversa e plural, que respeite e proteja as diversas manifestações culturais no ambiente escolar. Assim o princípio II orienta que haja "respeito à pluralidade, à diversidade, ao caráter laico da escola pública e aos direitos humanos em todas as instâncias da Rede Pública de Ensino do Distrito Federal". (DISTRITO FEDERAL, 2012). Em consonância com esse ordenamento Cury (2007) reafirma que a gestão democrática se configura na prática do diálogo e na busca de caminhos mais acessíveis e condizentes com a democratização da escola pública brasileira relacionada.

Entendemos ainda que a gestão escolar, uma vez composta por servidoras/es públicas/os é regida pelo princípio da impessoalidade da administração pública. A impessoalidade diz respeito ao fato de que a finalidade das ações, no exercício da função, devem priorizar sempre o interesse público em detrimento do 
individual/próprio ou mesmo de um pequeno conjunto de pessoas - em nosso caso, o corpo gestor, pois essas ações são imputadas à instituição e não a quem pratica. Logo, não é permitido ou ético sobrepor valores pessoais aos ordenamentos legais. Quanto a isso a CF/1988 traz a determinação de que "a administração pública direta e indireta de qualquer dos Poderes da União, dos Estados, do Distrito Federal e dos Municípios obedecerá aos princípios de legalidade, impessoalidade, moralidade, publicidade e eficiência" (BRASIL, 1988, grifo nosso).

Com essa aproximação entre gestão e ordenamentos procuramos enfatizar a responsabilidade constitutiva do exercício da administração escolar, e como isso deveria refletir na implementação da já apregoada - em diversas legislações educação diversa. Infelizmente, a inadequação às normas gestoras existe e resulta no fato de que ao não se reconhecer a necessidade de uma abordagem mais plural a "direção" escolar acaba por dar a essa prática uma dimensão que ultrapassa a individualidade, e alcança uma abrangência estrutural, onde toda a instituição se torna negligente e omissa.

Falando a partir da instituição na qual desenvolvemos nossas atividades durante os anos aos quais fazemos referência percebe-se que a equipe gestora possui conhecimento acerca das legislações, com destaque para a Lei 10.639/2003 e suas orientações, assim como conhecimento da necessidade de se reconhecer a diversidade e dos meios existentes para capacitação profissional, porém opta por não incluí-la nos documentos da instituição e tampouco em suas práticas pedagógicas. Não impede que educadoras/es o façam, porém de forma independente e solitária.

Quanto à postura da gestão escolar Garcia-Filice (2011) apresenta um estudo sobre as percepções de gestoras/es de diversos municípios por todo Brasil e do Distrito Federal e notou que alguns fatores foram bastante apontados como empecilhos à implementação da educação antirracista, desde formação profissional, material didático inadequado até a total desinformação da legislação 
educacional para as relações étnico-raciais. Esses foram os argumentos utilizados pela maioria das/os gestoras/es para justificar a não inclusão da temática, como recomendado, nas propostas, projetos e currículo das instituições, também não foi demonstrado qualquer preocupação, por parte da grande maioria, em buscar mecanismos para implementação dessa educação inclusiva.

Nessa pesquisa foram categorizados três perfis gestores, a saber: Gestão ausente/alheia seria aquela que se comporta de forma resistente às políticas educacionais afirmativas; Gestão sensível aquela que até se mostra sensível aos temas da diversidade, mas não apresenta interesse ou empenho e realiza apenas esporadicamente ações que valorizam a temática racial; e Gestão proativa que, em sua maioria, é exercida por ativistas nos movimentos sociais que, de alguma forma, já se encontram engajadas com as lutas pela igualdade. (GARCIA-FILICE, 2011)

Buscando relacionar nossa vivência às categorias apresentadas entendemos que a gestão a qual estivemos subordinadas é, segundo a tipificação de GarciaFilice, ausente/alheia, uma vez que, embora não se pronunciasse categoricamente contra e não interferisse em nossas iniciativas (aulas, projetos etc.), também não nos dava suporte, não realizou qualquer ação nesse sentido, nem mesmo esporadicamente se colocou como atuante para a implementação de uma educação igualitária. Ademais, mantém ainda uma visão nitidamente universalizante e contrária às políticas afirmativas, se baseia no discurso de que para alcançar a todas/os não se pode "privilegiar" os grupos historicamente excluídos - denominados de minorias, porque, segundo suas ideias, é dessa forma que não praticam o preconceito (GARCIA-FILICE, 2011).

Contudo, entendemos a gestão escolar como força motriz da ação afirmativa em busca de uma educação de qualidade com vistas à equiparação social, uma vez que tem função de liderança para a instituição e que, portanto, pode valorizar essa implementação ou, como vimos, simplesmente desconsiderá-la a partir de 
suas convicções pessoais. Nesse sentido falta o entendimento de que a gestão escolar, na figura da pessoa humana

é o representante maior da atividade-meio (a gestão), ou seja, aquela que deve oferecer sustentação à atividade-fim (ensino e aprendizagem), sem a qual não seria possível garantir o acesso de todos às aprendizagens na escola (LIMA, 2011, p. 3).

Nessa concepção a possibilidade de um exercício pleno dos direitos humanos está ligada de forma indissolúvel ao constante desenvolvimento da sociedade democrática, portanto, se faz inquestionável a necessidade de se trazer a questão da responsabilização gestora na implementação de leis que buscam a igualdade de direitos, sobretudo, o direito à educação de qualidade.

\section{CONSIDERAÇõEs FinaIS}

"[...] não há esperança na pura espera, nem tampouco se alcança o que se espera na espera pura, que vira, assim, espera vã." (Paulo Freire)

Longe de criar um imaginário de existência de fórmulas prontas ou de transmitir a pretensão de uma construção de orientações, e, ainda, respeitando as especificidades, não só das professoras/es que pretendemos que leiam este trabalho mas, sobretudo, das diversas comunidades escolares e suas particularidades, procuramos demonstrar que pequenas ações, independentes de conhecimento aprofundado ou apoio estrutural, podem proporcionar mudanças significativas e permitir o vislumbre de novos horizontes, mais equânimes e inclusivos.

Sabemos, porém, que, por mais simples que possam parecer, tais mudanças demandam força de vontade, e, mais ainda, força de vontade de mudança. Para tanto é preciso estarmos sensíveis para perceber, em nossas próprias práticas, ações que corroborem com uma possível perpetuação das desigualdades sociais É preciso assim parar e analisar as nossas atitudes com as crianças e jovens que passam por nossas vidas, verificar se estão contribuindo para que 
essas mazelas sociais se asseverem, dos quais elas/es serão apenas mais algumas pessoas vitimizadas, ou se, num outro nível, se tornarão conhecedoras/es de sua importância dentro de um projeto maior de nação, do qual a educação se torna base.

Nossa intenção, demonstrada em certa medida neste trabalho, pode soar um tanto quanto utópica, afinal almejar tais transformações sociais a partir de mudanças "tão simples" parece algo complicado certamente, porém, a certeza que sempre existiu é a de que pensar o novo nunca foi fácil. Mas ainda assim, e talvez por isso mesmo, é que continuamos pretendendo insuflar nos ideários de nossas/os colegas de profissão, e demais ledoras/es deste trabalho, que a capacidade transformadora das mudanças não se esmaecem quando realizadas a partir de um lócus micro (nossas salas de aula, por exemplo), pois sua abrangência maior se dará na ressonância das nossas práticas a partir destas pessoas em seus outros e demais espaços de convivência, fazendo daquele alcance tímido um resultado macro (na sociedade como um todo) construído em e pela irradiação de nossas práticas, o que observamos ter acontecido com nossas/os estudantes.

\section{REFERÊNCIAS}

ABRAMOVAY, Miriam; CUNHA, Anna Lúcia; CALAF, Priscila Pinto. Revelando tramas, descobrindo segredos: violência e convivência nas escolas. Brasília: Rede de Informação Tecnológica Latino-americana - RITLA, Secretaria de Estado de Educação do Distrito Federal - SEEDF, 2009. 496 p.

BARBOSA, Jaqueline A.; PAZ, Claudia Denis A. A opinião de professores/as sobre a influência do curso "Gênero e Diversidade na Escola" em suas práticas. In: SANTOS, Déborah; GARCIA-FILICE, Renísia Cristina; RODRIGUES, Ruth Meyre M (orgs). A transversalidade de Gênero e Raça nas Políticas Públicas: limites e possibilidades. São Paulo: Comunicação Integrada, 2015.

BRASIL. Constituição Federal, de 05.10.88. Atualizada com as Emendas Constitucionais Promulgadas.

BRASIL. Ministério da Educação. Secretaria da Educação Continuada, Alfabetização e Diversidade. Gênero e Diversidade Sexual na escola: 
Reconhecer Diferenças, Superar Preconceitos. Brasília: SECAD, 2007. Disponível em: http://portal.mec.gov.br/secad/arquivos/pdf/escola protege/caderno5.pdf

. Ministério da Educação. Secretaria da Educação Continuada, Alfabetização e Diversidade..Educação integral: texto referência para o debate nacional. Brasília, 2009. 52 p. : il. - (Série Mais Educação) Disponível em: http://portal.mec.gov.br/dmdocuments/cadfinal educ integral.pdf

. Educação anti-racista: caminhos abertos pela Lei Federal no 10.639/03 / Organizador, Sales Augusto dos Santos. - Brasília: SECAD, 2005. Disponível em: http://portal.mec.gov.br/index.php?option=com content\&view=article\&id=137 88\%3Adiversidade-etnico-racial\&catid=194\%3Asecad-educacaocontinuada\&ltemid $=913$

CARVALHO, Marília Pinto de. Mau aluno, boa aluna. Como as professoras avaliam meninas e meninos. Rev. Estud. fem., 2001, vol. 9 n. 2 p. 554-574. http://dx.doi.org/10.1590/S0104-026X2001000200013

. Marília Pinto de. O fracasso escolar de meninos e meninas: articulações entre gênero e cor/raça. Cadernos Pagu (22), 2004 p. 247-290. http://dx.doi.org/10.1590/S0104-83332004000100010.

. Marília Pinto de. Avaliação escolar, gênero e raça. Campinas/SP: Papirus, 2009.

CURY, Carlos Roberto Jamil. A gestão democrática na escola e o direito à educação. Revista Brasileira de Política e Administração da Educação. V. 23. N.3 set./dez, 2007. p. 483-495.

DISTRITO FEDERAL. LEI № 4.751, de 7 de fevereiro de 2012.Dispõe sobre o Sistema de Ensino e a Gestão Democrática do Sistema de Ensino Público do Distrito Federal.(Autoria do Projeto: Poder Executivo).

GARCIA-FILICE, R.C. Raça e classe na gestão da educação básica brasileira a importância da cultura na implementação de políticas públicas. Campinas: Autores Associados, 2011.

JARDIM, Silvia Regina Marques \& ABRAMOWICZ, Anete. Tendências da produção paulista sobre gênero e educação: um balanço de dissertações de mestrado. RBPG, v.2, n.3, p.93 a 117, março de 2005.

LIMA, Erisevelton Silva. O Diretor e as avaliações praticadas na escola. Editora Kiron: Brasília-DF, 2011. p. $51-55$.

SACRISTÁN, José Gimeno. Org. Saberes e Incertezas sobre o Currículo. Trad. Alexandre Salvaterra. Porto Alegre: Penso, 2013. 542 p.

SILVA, Tomaz Tadeu da. Quem escondeu o currículo oculto? In: Documentos de identidade: uma introdução às teorias do currículo. Belo Horizonte: Autêntica, 1999. 